\title{
DIAGNOSTICS
}

\section{Detection of varicella zoster virus in genital specimens using a multiplex polymerase chain reaction}

\author{
C J Birch, J D Druce, M C Catton, L MacGregor, T Read
}

Sex Transm Infect 2003;79:298-300

See end of article for authors' affiliations

Correspondence to: Chris Birch, 10 Wreckyn Street, North Melbourne 3051, Victoria, Australia chris.birch@mh.org.au

Accepted for publication 13 December 2002

\begin{abstract}
Objective: To compare the relative proportions of varicella zoster virus (VZV) and herpes simplex viruses in specimens obtained from the genital lesions of adults presenting with presumed genital herpes infection.

Methods: Swabs of genital lesions from 6210 patients attending general practices, infectious diseases clinics within hospitals, or sexual health centres for treatment of their genital lesions were tested using polymerase chain reaction (PCR) technology. The multiplexed PCR was capable of detecting herpes simplex virus types 1 and 2 (HSV-1, HSV-2), VZV, and cytomegalovirus in a single sample.

Results: A total of 2225 patients had viruses detected by PCR. HSV-1 was detected in $36 \%$, HSV-2 in $61 \%$, and VZV in $2.9 \%$ of PCR positive samples. Of the 65 patients with VZV genital infection, many were thought to have HSV infection before laboratory testing.

Conclusions: The finding of VZV in nearly $3 \%$ of virus positive genital specimens demonstrates that this virus needs to be considered as a differential diagnosis for genital herpetic lesions. Advice provided to patients with VZV genital infection regarding the source of infection, likelihood of recurrence, and potential for transmission of the virus will be different from that given to patients with HSV infection.
\end{abstract}

V aricella zoster virus (VZV) causes chickenpox and, in its recurrent form, shingles. Zoster can occur at all ages, but is more common in those aged over 50 (www.harrisonsonline.com). Individual cases of recognised vulval $^{1}$ and anogenital ${ }^{2}$ infection with VZV have been described in adults, and cases of genital infection with this agent in children have also been reported..$^{3-4}$ In some circumstances infections in children have required laboratory confirmation to eliminate accusations of child abuse when infection with herpes simplex virus (HSV) was suspected. However, we are unable to find any reports describing the incidence of VZV in genital lesions of adults presenting with presumed HSV infection.

Polymerase chain reaction (PCR) technology has increased the sensitivity of detection of viruses such as VZV over methods such as virus isolation or direct immunofluorescence. ${ }^{5}$ In particular, the slower replication in vitro of VZV compared to HSV by up to 10 days in some cases may result in virus isolation attempts being abandoned as negative when the clinical diagnosis is HSV infection, resulting in the occasional failure to isolate VZV. Historically, therefore, the incidence of VZV associated genital infection is likely to have been underreported. We describe here the results of a study investigating the incidence of herpesvirus infections in genital specimens using a multiplex PCR that detects and differentiates between HSV-1, HSV-2, cytomegalovirus (CMV), and VZV.

\section{MATERIALS AND METHODS}

\section{Patients and specimens}

Specimens were received from 6210 patients who attended general practices, infectious diseases clinics within hospitals, or sexual health centres for treatment of genital lesions. With the permission of the patients, swabs of lesions thought to be of viral aetiology were sent to the laboratory for PCR testing. The clinical diagnosis was inferred from the herpesvirus type written on the request form by the clinician ordering the test: VZV, HSV, and either VZV or HSV. If the clinician did not specify any herpesvirus, the clinical diagnosis was recorded as "no diagnosis." The study was carried out on specimens tested between October 1999 and December 2001.

\section{Multiplex PCR assay to detect herpesviruses}

The PCR assay used to detect HSV-1, HSV-2, CMV, and VZV DNA in clinical material has been described previously. ${ }^{5}$ Briefly, specimens were vortexed and DNA extracted by treating $40 \mu \mathrm{l}$ of specimen with $2 \mu \mathrm{l}$ \% Nonidet P40 at $70^{\circ} \mathrm{C}$ for 45 seconds. Nested PCR was performed using primers specific for HSV (both serotypes 1 and 2), HSV-2, CMV, and VZV. Primers specific for equine herpesvirus type 4 were also included to amplify this virus, which was added to each sample at the time of DNA extraction to serve as an internal amplification control. Amplified products were electrophoresed in 2\% agarose gels, stained in ethidium bromide and photographed using a Gel Doc 2000 (Biorad, USA). All bands were interpreted qualitatively. A typical gel is shown in figure 1 .

\section{Statistical analysis}

The proportion of requests where the possibility of VZV was noted was compared to requests where VZV was not indicated using two sample comparisons of proportion.

\section{RESULTS}

Proportions of HSV-1, HSV-2, VZV, and CMV in genital specimens

A total of 6210 genital swabs were sent to the laboratory for testing using the multiplex herpesvirus PCR during the period October 1999 to December 2001 (table 1). At least one of the viruses represented in the assay was found in 2255 of these specimens $(36.3 \%)$. HSV-2 was the most common virus detected (61\% of all positives); HSV-1 was present in $36 \%$ of specimens and VZV in $2.9 \%$ (table 1 ). CMV was seen in low numbers (five of 2255 positive samples $(0.2 \%)$ ). All of the CMV positive specimens were from females (result not shown). In these cases the CMV DNA detected was assumed to represent urine contamination of the specimen rather than to implicate CMV as a causative agent of genital infection.

\section{Patients positive for VZV DNA}

The age range, sex, and diagnosis at presentation of the 65 patients (25 male, 40 female) with genital lesions positive for VZV DNA is shown in table 2 . Of the 25 males positive for VZV 


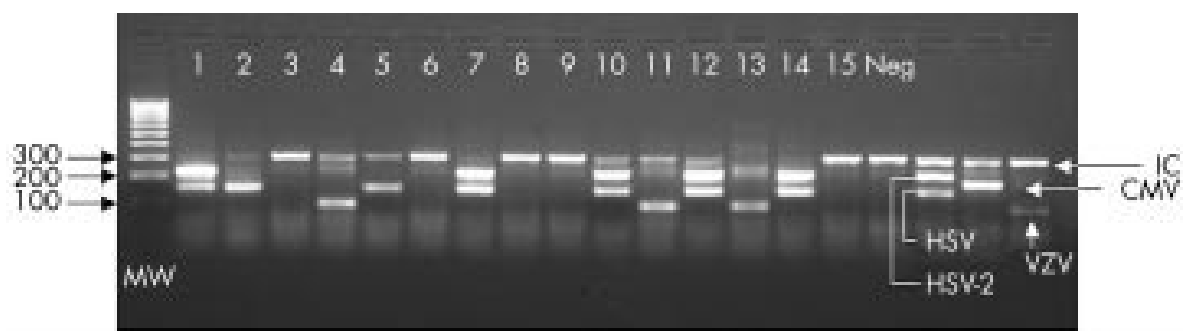

Figure 1 Products seen by gel electrophoresis following two rounds of the multiplex herpesvirus PCR. The material in lanes 1-15 was derived from genital swabs. Specimens in lanes 1, 7, 10, 12, and 14 contain HSV-2 DNA. Lanes 2 and 5 contain HSV-1 DNA; lanes 4, 11 , and 13 are positive for VZV DNA; lanes $3,6,8,9$, and 15 are negative. Molecular weight markers with representative weights (in base pairs) are shown in the extreme left lane. Negative (Neg), HSV-2, CMV, and VZV controls are shown in the right hand lanes. The position of the internal control (IC) band is indicated.

Table 1 Comparative detection rates by PCR of HSV-1, HSV-2, CMV, and VZV in genital swabs

\begin{tabular}{lllll}
\hline \multirow{2}{*}{ No tested } & \multicolumn{4}{l}{ Number positive (\% of positives) } \\
\cline { 2 - 5 } & HSV-1 & HSV-2 & CMV & VZV \\
\hline 6210 & $813(36)$ & $1372(61)$ & $5(0.2)$ & $65(2.9)$ \\
\hline
\end{tabular}

Table 2 Age range, sex, and clinical diagnosis of 65 patients whose genital specimens contained VZV DNA

\begin{tabular}{llllll}
\hline & & \multicolumn{3}{c}{ Clinical diagnosis* } & \\
\cline { 3 - 4 } $\begin{array}{l}\text { Age } \\
\text { (years) }\end{array}$ & $\begin{array}{l}\text { Patients } \\
\text { (males, females) }\end{array}$ & VZV & $\begin{array}{l}\text { VZV and } \\
\text { HSV }\end{array}$ & HSV & Nonet \\
\hline $0-15$ & $7(2,5)$ & 2 & 2 & 0 & 3 \\
$16-50$ & $37(17,20)$ & 0 & 5 & 13 & 19 \\
$>50$ & $21(6,15)$ & 3 & 3 & 3 & 12 \\
Total & $65(25,40)$ & 5 & 10 & 16 & 34 \\
\hline
\end{tabular}

*Patients with genital lesions and VZV and/or HSV included in the differential diagnosis.

†Patients with genital lesions but no diagnosis recorded.

DNA, the virus was detected in swabs collected from penile (10), groin (seven), "genital" (three), perianal (three), and scrotal (two) sites. Of the 40 females positive for the virus, swabs were obtained from vulval (14), labial (six), "genital" (six), groin (six), vaginal (four), and perianal (four) sites. Overall, 15 of 65 VZV positive swabs had clinical notes querying VZV (that is, either VZV alone or VZV and HSV recorded on the request form). Of these, five had VZV alone and 10 had both VZV and HSV. A total of 16 requests specified HSV alone. Approximately half of all requests (34 of 65) had no provisional diagnosis recorded. VZV DNA positive specimens associated with a differential diagnosis that included VZV were more likely to come from patients attending general practitioners and hospital infectious diseases clinics (14/56) than sexual health clinics (one of nine), although the difference was non-significant $(p=0.36)$.

VZV infection was more likely to be considered in younger and older age groups. In the age group less than 15 years, four of the seven patients had VZV noted on their request forms. This proportion was significantly greater than among the predominant $16-50$ year age group $(p=0.009)$. In the $16-50$ age group, five of 37 patients had VZV noted on their request forms, while in the oldest age group (older than 50 years) six of 21 patients had VZV noted on their request forms. While the latter were more likely to have VZV noted compared to the 16-50 age group, the difference was not statistically significant $(\mathrm{p}=0.16)$.

The risk factors and symptoms of four of the patients diagnosed clinically as having HSV infection are shown in table 3. Despite the availability of a detailed history and examination of their genital lesions by an experienced physician, each patient was thought to have an HSV infection before laboratory testing.

\section{DISCUSSION}

Of 2255 specimens positive for at least one of HSV-1, HSV-2, VZV, and CMV, 65 (2.9\%) were positive for the presence of VZV DNA. Although some of these infections were diagnosed at the time of presentation as being likely to be caused by VZV, more were thought to be cases of HSV infection. Our study highlights that a small but significant number of cases of presumed genital HSV infection are caused by VZV, and that

Table 3 Risk factors and symptoms at presentation of 4 patients with presumed genital HSV infection in whom VZV DNA was detected in lesions by PCR

\begin{tabular}{|c|c|c|c|c|c|}
\hline Sex (age) & Risk factors & Symptoms at presentation & Clinical diagnosis & Treatment & $\begin{array}{l}\text { PCR } \\
\text { result }\end{array}$ \\
\hline Male (44) & $\begin{array}{l}\text { HIV positive, viral load }<500 \text { copies } \\
\times 10^{\circ} / \mathrm{l}, \mathrm{CD} 4+\text { cells }=780 \times 10^{6} / \mathrm{l}\end{array}$ & $\begin{array}{l}\text { Painless bilateral ulcers on base of penis. } \\
4 \text { days' duration }\end{array}$ & HSV genital infection & None & VZV \\
\hline Male (34) & $\begin{array}{l}\text { Intercourse with female sex worker } 5 \\
\text { weeks earlier }\end{array}$ & $\begin{array}{l}\text { Painless red vesicles ajacent to urethral } \\
\text { meatus. } 6 \text { days' duration }\end{array}$ & $\begin{array}{l}\text { HSV genital infection } \\
\text { or dermatitis }\end{array}$ & None & VZV \\
\hline Male (21) & Sex with female partner 1 day earlier & $\begin{array}{l}\text { Paraesthesiae (leg). Vesicles on left buttock, } \\
\text { perineum, left hemiscrotum and penis. } \\
\text { Tender left inguinal node }\end{array}$ & HSV infection & $\begin{array}{l}\text { Oral valaciclovir, } \\
\text { topical aciclovir }\end{array}$ & VZV \\
\hline Female (31) & Past history of genital herpes infection & $\begin{array}{l}\text { Vulval sores resembling small tears on } \\
\text { either side of vaginal introitus }\end{array}$ & HSV genital infection & $\begin{array}{l}\text { Clioquinol cream with } \\
\text { topical hydrocortisone }\end{array}$ & VZV \\
\hline
\end{tabular}


zoster needs to be considered as a differential diagnosis for genital herpetic lesions. Zoster is said to most frequently affect the T3 to L3 dermatomes (www.harrisonsonline.com), but our findings suggest the frequency of genital zoster may be under-recognised.

This study is limited by the quality of the clinical diagnoses recorded on the request forms. Approximately half of the specimens were not accompanied by a clinical diagnosis and we cannot be certain that the virus named on the pathology request form was the most likely clinical diagnosis in every case. But the appearance of HSV on request forms more often than VZV likely represents under-recognition of genital VZV.

Clinical distinction between HSV and VZV infections does not usually present difficulties, although if correct diagnosis is an issue the tendency for recurrence and the restriction to a smaller part of the dermatome suggests HSV infection. ${ }^{6}$ Distinction of VZV associated genital infection from that caused by HSV-1 or HSV-2 is important for several reasons. Because VZV genital infections are not as common as those associated with HSV infection, and recurrences would not be expected, at least in immunocompetent individuals, ${ }^{7}$ their clinical significance and the potential for sexual transmission may be diminished. For many individuals, genital infection with VZV and its association with a common primary infection of childhood are also less likely to have the psychological impact of sexually transmitted HSV-1 or HSV-2 infections.

Antiviral therapy for VZV or HSV associated infections, if indicated, is likely to involve the use of famciclovir ${ }^{8}$ or valaciclovir.' If HSV infection is assumed, the recommended dose of either of these drugs may be less effective when the lesions are caused by VZV, since higher doses are required for effective VZV therapy compared to those required for treatment of HSV infection. ${ }^{10}$ However, the increasing availability of PCR technology with its associated rapid turnaround time improves the likelihood that optimal therapeutic decisions will be made.

The detection of VZV in genital specimens highlights the sensitivity and versatility of molecular based techniques such as PCR, which are being increasingly used in virus diagnostic laboratories. These tests are replacing virus isolation methods which, although sensitive for the detection of HSV-1 and HSV-2 within an a short time frame (4-7 days), are less so for $V Z V$, which takes longer to replicate. While the incidence of VZV associated genital infection was low in our population compared to HSV-l and HSV-2 infection, it was not the expected causative agent in the majority of the 65 patients in whom it was identified. Advice provided to patients regarding the source of their infection, likelihood of recurrence, and potential for transmission of $\mathrm{VZV}$, and their response to this advice, is likely to be substantially different from that given to patients with HSV-1 or HSV-2 infection. Thus, doctors and

\section{Key messages}

- VZV was present in $2.9 \%$ of patients presenting with genital infections.

- VZV may be an under-reported cause of viral genital infections, especially in patients $16-50$ years of age.

- VZV should be included in the differential diagnosis of viral genital infection.

- PCR has increased the likelihood that VZV will be detected in genital lesions.

virologists should consider the possibility of VZV in patients presenting with genital infection, and test accordingly.

\section{CONTRIBUTORS}

$\mathrm{CJB}$, senior scientist with responsibility for diagnostic testing in the area described, input into the design, validation, and performance of the PCR, responsible for preparation of the manuscript; JDD, senior scientist with input into the design, validation, and performance of the PCR, and assistance with collation of data for input into the manuscript; MCC, medical virologist, assistance with preparation and review of the manuscript; LMacG, statistician, and assistance with preparation and review of the manuscript; TR, clinician, with special expertise in the diagnosis of sexually transmitted infections, input into preparation and review of the manuscript.

\section{Authors' affiliations}

C J Birch, J D Druce, M C Catton, Victorian Infectious Diseases Reference Laboratory, North Melbourne, Australia

L MacGregor, Royal Melbourne Hospital, Parkville, Australia

T Read, Melbourne Sexual Health Clinic, Melbourne, Victoria, Australia

\section{REFERENCES}

1 Brown D. Herpes zoster of the vulva. Clin Obstet Gynaecol 1972:15:1010-14.

2 Roupe G. Anogenital herpes zoster in two cases of Wegener's granulomatosis. Br J Dermatol 1973;89:285-8.

3 Simon HK, Steel DW. Varicella: pediatric genital/rectal vesicular lesions of unclear origin. Ann Emerg Med 1995;25:111-14.

4 Christian CW, Singer ML, Crawford JE, et al. Perianal herpes zoster presenting as suspected child abuse. Pediatrics 1997;99:608-10.

5 Druce J, Catton M, Chibo D, et al. Utility of a multiplex PCR assay to detect herpesvirus DNA in clinical samples. J Clin Microbiol 2002;40:1728-32.

6 Peterslund NA. Herpesvirus infection: an overview of the clinical manifestations. Scand J Infect (Suppl) 1991;78:15-20.

7 Liesegang TJ. Varicella zoster viral disease. Mayo Clin Proc 1999;74:983-98

8 Sacks SL, Aoki FY, Diaz-Mitoma F, et al. Patient-initiated, twice-daily ora famciclovir for early recurrent genital herpes: a randomized, double-blind multicenter trial. JAMA 1996;276:44-9.

9 Beutner KR, Friedman DJ, Forszpaniak C, et al. Valacyclovir compared acyclovir for improved therapy for herpes zoster in immunocompetent adults. Antimicrob Agents Chemother 1995;39:1546-53.

10 Erlich KS. Management of herpes simplex and varicella-zoster virus infections. Western J Med 1997; 166:211-15. 